\title{
The impact of walkable environment on single-family residential property values
}

\author{
Yuntao Guo \\ Purdue University \\ guo187@purdue.edu
}

\author{
Srinivas Peeta \\ Purdue University \\ peeta@purdue.edu
}

\section{Sekhar Somenahalli \\ University of South Australia \\ Sekhar.Somenahalli@unisa.edu.au}

Abstract: Due to the impact of urban sprawl, the need for responsible property investing, and the emerging evidence supporting the linkage between walkable environment (in terms of built environment and walk accessibility) and residential property value, there is a critical need to develop systematic methodologies to quantify the impact of walkable environment on residential property value. This study provides a new generalized dissimilarity index for quantifying landuse mix, a key component of built environment, and a new method for measuring a property's walk accessibility and then links them to residential property values. Ordinary least squares (OLS) regression models are used to validate these methods by examining the empirical property data in Eastern Adelaide, Australia. The results of the OLS models show that the proposed dissimilarity index and property walkaccessibility method outperform other commonly used land-use mix quantification and walk-accessibility methods in estimating singlefamily residential property values in terms of the goodness-of-fit and explanatory power. This study provides insights for investors to understand the impact of walkable environment on single-family residential property values to enable them to make more informed decisions on property investment, and for planners to design neighborhoods featuring better walkable environments.

\section{Article history:}

Received: April 29, 2015

Accepted: June 17, 2015

Available online: September 21, 2015

\section{Introduction}

Over the past decade, extensive studies have been performed to address the negative impact of landuse zoning ordinances that result in most residential properties being developed at locations featuring highly segregated land uses and curvilinear or cul-de-sac street patterns (Matthews and Turnbull 2007). Substantial distances have been created between residential properties, commercial properties, and ser-

Copyright 2015 Yuntao Guo, Srinivas Peeta \& Sekhar Somenahalli http://dx.doi.org/10.5198/jtlu.2017.824

ISSN: 1938-7849 | Licensed under the Creative Commons Attribution - Noncommercial License 3.0

The Journal of Transport and Land Use is the official journal of the World Society for Transport and Land Use (WSTLUR) and is published and sponsored by the University of Minnesota Center for Transportation Studies. 
vices locations. This practice leads to social and economic issues such as traffic congestion, air pollution, and job-housing imbalance, etc. The concept of designing a more walkable environment that embodies principles of new urbanism (Congress of New Urbanism 2014) has been considered as one of the solutions to this complex problem. A walkable environment is defined as a neighborhood with physical attributes that encourage walking for functional and recreational purposes. Numerous studies have addressed the impact of a walkable environment on a variety of transportation-related environmental and social benefits. The potential environmental benefits of a more walkable environment include improved air quality (Frank, Stone, and Bachman 2000), and reduced traffic congestion (Ewing and Cervero 2001) and gasoline consumption (Ewing and Rong 2008). Possible social benefits include promoting active travel (Rodríguez et al. 2009) and increasing social capital and quality of life with greater community cohesion, trust, reciprocity, and diversified social activities among citizens (Leyden 2003).

Apart from the potential environmental and social benefits, recent empirical studies also illustrate that a more walkable environment can improve residential and commercial property values (Pivo and Fisher 2009; Boyle, Barrilleaux, and Scheller 2013). In addition, the emerging domain of responsible property investing (Pivo and Fisher 2009) seeks to promote real estate investments that benefit both investors and the common good. The methods and terminologies used are different given the large number of potential factors in the context of walkable environment (Congress of New Urbanism 2014). As the interest increases for developing more walkable environments (Levine and Inam 2004), systematic methodologies are needed to characterize and quantify walkable environments by leveraging available social and demographic information. The development of desktop and mobile web mapping service applications can also serve an important role in assisting the residential housing development and planning process. The proposed study seeks to develop systematic methodologies and leverage desktop/mobile mapping service applications to quantify the walkable environment (in terms of built environment and walk accessibility) and its impact on the residential property values. Built environment represents the urban form of the neighborhood, including density, diversity, and design of a neighborhood (Cervero and Kockelman 1997). Walk accessibility quantifies the ability to access different services/destinations from a property at a micro-scale level. Based on the generalized definition of accessibility (Chen et al. 2011), a residential property's walk accessibility is defined as the ease with which opportunities for activity can be reached by walking from that property. Previous studies (e.g., Manaugh and Kreider 2013) proposed different methods to quantify walkable environment or attempted to address the potential impact of walkable environment on property values, but these methods often have either methodological or applicability limitations.

In this study, a new generalized dissimilarity index for land-use mix quantification, and a new approach to calculate property walk accessibility are proposed to quantify the walkable environment to address the limitations of previous methods. To validate the two proposed methods, ordinary least squares (OLS) regression models were constructed to compare with other commonly used land-use mix and walk accessibility methods, and empirical property data from Eastern Adelaide, Australia, was used for the comparison in terms of the goodness-of-fit and explanatory power. The model insights can help investors to understand the impact of walkable environment on the single-family residential property value to aid them to make more informed decisions on property investment. In addition, they can also assist planners to design neighborhoods with a better walkable environment to enable transportationrelated environmental and social benefits, as well as financial benefits to the residents.

The remainder of the paper is organized as follows. Section 2 describes the methods used in the literature to quantify built environment and property walk accessibility. Section 3 proposes a new (generalized) dissimilarity index for land-use mix quantification, a key component of built environment, and a new approach to calculate property walk accessibility. Section 4 discusses data acquisition for the 
Eastern Adelaide Government Region (or the Eastern Adelaide region), Australia, which is used as a case study to analyze the impact of built environment and property walk accessibility on the single-family residential property value. Section 5 discusses numerical experiments using the case study, compares the performance of the proposed land-use mix quantification and walk accessibility methods with other commonly used ones, and analyzes the case study results to provide insights. Section 6 provides some concluding comments.

\section{Literature review}

Several studies have been performed to quantify walkable environment and address the potential benefits of walkable environment on residential property value. Built environment and property walk accessibility were identified as two major components for quantifying walkable environment and understanding the impact of walkable environment on residential property value. Sections 2.1 and 2.2 review the methodologies used to quantify built environment and walk accessibility, respectively. Section 2.3 reviews studies that focus on understanding the impact of built environment and/or walk accessibility on residential property value.

\subsection{Methods to quantify walkable environment}

Several potential factors have been studied to quantify the built environment. They include street connectivity, sidewalk availability (McCormack et al. 2012), expert opinion (Saelens, Sallis, and Frank 2003), residents' perception (Cerin et al. 2007), census data, and land-use mix (Matthews, and Turnbull 2007). Given the large number of potential factors that can be used to quantify built environment, Frank et al. (2010) introduced the concept of "walkability index" based on conceptual and empirical literature data, by factoring density, mixed land use, and connectivity. Four key components were included in the study: 1) net residential density (population divided by total residential land area), 2) retail floor area ratio (retail building floor area footprint divided by retail land floor area footprint), 3) intersection density (ratio between number of intersections to total land area), and 4) land-use mix using the entropy index (ENT) method. Frank et al. provides a practical starting point to quantify walkable environment since all the variables included are widely available in existing datasets. However, the entropy index method used to calculate the land-use mix has two potential limitations that may impact the performance of walkability index. Equation 1 shows the general form of the entropy index calculation (Song, Merlin, and Rodriguez 2013),

$$
E N T=-\frac{\left[\sum_{j=1}^{k} P_{j} \ln \left(P_{j}\right)\right]}{\ln (k)}
$$

where $P_{j}$ is the percentage of each land-use type $j$ in the area and $k$ is the number of land-use types $j$. The first limitation related to entropy index is that it fails to consider the micro-scalevariation within the neighborhood. Figure 1 presents four different neighborhoods in terms oflayout and scale. Dotted lines represent the neighborhood boundaries and solid lines represent streets. The shaded areas indicate nonresidential properties and the non-shaded areas represent residential properties. Both neighborhoods in Figures $1(\mathrm{a})$ and $1(\mathrm{~b})$ contain 16 properties of the same size $(0.25 \mathrm{mile} \times 0.25$ mile). Each neighborhood includes eight residential properties and eight non-residential properties. Figures 1(a) and 1(b) present two neighborhoods with the same land-use mix value using the entropy index; ENT is equal to one for both neighborhoods, representing the highest land-use mix. However, the entropy index cannot reflect the different spatial arrangements of residential and non-residential properties, which can greatly impact the level of access and connectivity in neighborhoods. For example, the average walking distance from 
the centroid of a residential property to the centroid of the nearest non-residential property is 0.25 miles in the neighborhood in Figure 1(a), but the average walking distance is double that in the neighborhood shown in Figure 1(b).

1(a)

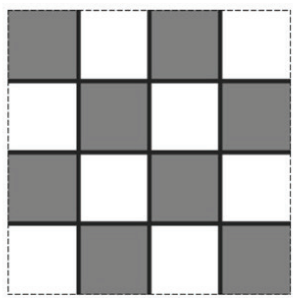

1(c)
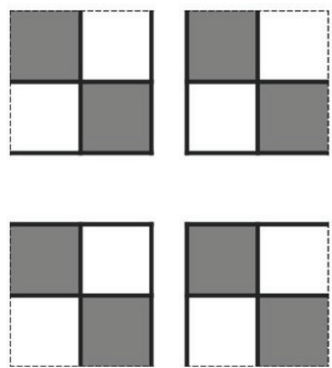

$1(b)$

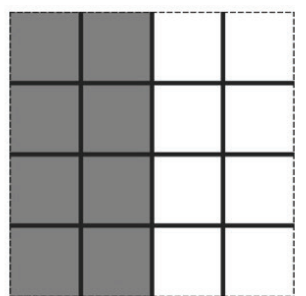

1(d)
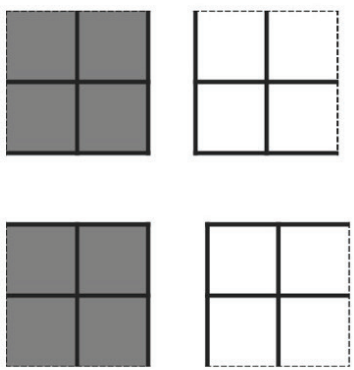

Figure 1: Neighborhoods with different land-use patterns

The second limitation of entropy index is that it is sensitive to the size of the neighborhood considered. Figures 1(c) and 1(d) are the neighborhoods created by further dividing neighborhoods in Figures 1(a) and 1(b), respectively, into four equal-sized parts. The land-use mix for the four smaller neighborhoods in Figure 1(c) remains identical to that for the neighborhood in Figure 1(a). However, the land-use mix values for the four smaller neighborhoods in Figure 1(d) reduce from the highest (one) to the lowest (zero).

To address the limitations of using entropy index to quantify land-use mix, a dissimilarity index and an interaction index were introduced in previous studies. Cervero and Kockelman (1997) introduced a dissimilarity index (Equation 2) to represent the impact of land-use diversity on travel demand. It is calculated based on measuring the proportion of dissimilar land uses among hectare grid-cells within a census tract. For each tract, it is computed as:

$$
\text { land use mix }=\sum_{k} \frac{1}{K} \sum_{i=1}^{8} \frac{X_{i k}}{8}
$$

where $K$ is the number of actively developed hectare grid-cells in a tract, and $X_{i k}=1$ if the land use type of the active center grid-cell $k$ differs from that of a neighboring hectare grid-cell $i$ ( 0 otherwise). The number 8 in the equation represents the eight neighboring parcels of the hectare grid-cell $k$. The major advantage of using this dissimilarity index is that it can address both the aforementioned limitations of entropy index. It considers the micro-scale variation within the neighborhood. For the neighborhoods in Figures 1(a) and 1(b), the micro-scale variation within the neighborhood is reflected using this dissimilarity index as the neighborhood in Figure 1(a) has a higher land-use mix value (0.59) and the neighborhood in Figure 1(b) has a lower land-use mix value (0.19). This dissimilarity index is not sensitive to the size of the neighborhood as the land-use mix values for the neighborhoods in Figures 1(c) and 1(d) are identical to those for the neighborhoods in Figures 1(a) and 1(b), respectively. However, the key 
limitation of the dissimilarity index proposed by Cervero and Kockelman (1997) is that it requires the land-use data to be recorded at the hectare grid-cell level. The underlying assumption for this method is that within one hectare grid-cell, there can only be one type of land use. In the real world, the land-use data is often not recorded at the hectare grid-cell level. Also, each individual land-use parcel varies significantly in size and shape, making it intractable to quantify the land-use type at hectare grid-cell level.

Manaugh and Kreider (2013) propose the interaction method to improve the measurement of land-use mix. It calculates the land-use mix by dividing the length of the interaction lines between different land-use types within a census collection district by the size of the census collection district. This study shows that its method performs better than the entropy index in estimating the percentage of people that uses walking or bicycling as the primary mode to work. However, this method may not be the best fit for some types of land-use situations where there are significant gaps between different land-uses parcels. The existence of these gaps varies, as some gaps are caused by the presence of road networks while others are due to a river, lake, or Indian reservation. For any data with such gaps, the results generated by the interaction method would not be sufficient to reflect land-use mix as the length of the interaction lines between different land-use types may be significantly reduced.

The aforementioned methods to quantify land-use mix have either methodological or applicability limitations. Hence, a new method to quantify the land-use mix is needed to address these limitations.

\subsection{Methods to quantify walk accessibility}

The property walk accessibility is defined as the ease of access to different types of opportunities by walking from a residential property. Some studies (Pivo and Fisher 2009; Boyle, Barrilleaux, and Scheller 2013) use walk score (Walk Score 2014) to quantify walk accessibility and its impact on residential, retail, and industrial property values. Walk score is calculated by measuring the straight-line distance between a property and its nearest educational, retail, food, recreational, and entertainment destinations. A score is assigned to each category and summed to generate a score between 0 and 100 . A higher walk score indicates a property has better access to different services. While it provides an easy way to quantify a property's walk accessibility, it has four limitations. First, the walk score calculation only considers a property's distance to the nearest destination. It does not consider that a property with multiple destinations (e.g., grocery stores) within walking distance has a higher walk accessibility than a property with only one destination. Second, it fails to address the impact of neighborhood layout on walking distance and time. By only measuring the straight-line distance between a property and its potential destinations, it does not consider street patterns, connectivity, physical barriers, and neighborhood topography. This would result in underestimating the walking distance and time to reach the intended destinations. Third, it assigns equal weight to all destinations in terms of size and purpose. This fails to consider that people may consider a large department store with more selection options more attractive than a smaller convenience store with limited options. Fourth, Lee and Moudon (2006) found that some destinations (e.g., grocery stores) are more associated with home-based walking than other destinations (e.g., movie theaters). It indicates that the accessibility to some types of locations may have a larger impact on residents' home-based walking distance than accessibility to other types of locations.

The Hansen-gravity accessibility measures and the class of floating catchment methods (FCMs) are considered the two most common robust approaches to quantify automobile or transit accessibility, but few studies use them to quantify walk accessibility. The Hansen-gravity accessibility measure is considered more conceptually complete, but is not intuitive to interpret and requires more data for calculation (Manaugh and Kreider 2013). The FCM is a relatively new method to calculate accessibility (Equation 3). It has advantages similar to a gravity model, and is also more intuitive to interpret (Manaugh and Kreider 2013). The accessibility $F C M_{i}$ of property $i$ is calculated as follows. Given a property $i$, search all 
the intended destinations $j$ (e.g., restaurants) within a threshold walking time $\left(d_{0}\right)$. Then,

$$
F C M_{i}=\sum_{j \in\left\{d_{i j} \leq d_{0}\right)} S_{j}
$$

where $d_{i j}$ is the walking time between $i$ and $j$, and $S_{j}$ is the weight of destination $j$. The FCM has been increasingly used in health applications (e.g., Song, Merlin, and Rodriguez 2013) and nonhealth- based studies (e.g., Manaugh and Kreider 2013). It addresses the first aforementioned limitation of using walk score by factoring multiple accessible destinations within the walk range (by adding $d_{0}$, the threshold walking time). However, all intended destinations within a threshold walking time are weighted only by their sizes and not their distance to the property (the second limitation of walk score). For example, two convenience stores with the same size located at 5 minutes and 20 minutes from the property would be weighted equally if the threshold walking time is 30 minutes.

A new method to quantify a property's walk accessibility is needed to address the limitations of the walk score and FCM methods.

\subsection{The impact of walkable environment on residential property value}

In previous studies (e.g., Pivo and Fisher 2009), global regression models (e.g., OLS regression or hedonic price models) are often used to study the impact of a walkable environment related attribute (either land-use mix or walk accessibility) on residential property value. For example, Song and Knaap (2004) used entropy index method to study the impact of land-use mix on residential property values. They found that residential property values are higher in neighborhoods with low land-use mix, where the land use is dominated by single-family residences. Pivo and Fisher (2009) used the walk score to study the impact of walk accessibility on office, apartment, retail, and industrial property values in the United States. They found that, all else being equal, a property with a higher walk score can increase the property value of office, apartment, and retail properties. But no effect of walk score was found related to industrial property value. However, these studies only apply to the aforementioned commonly used quantification methods of land-use mix and walk accessibility, which due to issues discussed in Sections 2.1 and 2.2 may not be able to accurately capture the impact of walkable environment on residential property value or cannot be applied to some datasets.

This study proposes new methods to quantify land-use mix (generalized dissimilarity index) and property walk accessibility. To validate them, OLS models are applied to compare the model fit of the proposed methods with those of existing ones discussed in Sections 2.1 and 2.2.

\section{$3 \quad$ Methodology}

As discussed heretofore, there are limitations in existing studies related to the quantification of built environment and walk accessibility. Further, they cannot capture the spatial non-stationarity associated with the impacts of built environment and walk accessibility on residential property values. This section describes the proposed methods used to quantify built environment and property walk accessibility.

\subsection{Built environment}

The study uses the following approach to quantify built environment. Residential density, a generalized dissimilarity index for land-use mix, and intersection density are introduced to address the three aspects of built environment: density, diversity, and design, respectively.

A generalized dissimilarity index (DIS) is introduced (Equation 4) to quantify land-use mix instead of entropy index, 


$$
\text { DIS }=\frac{\sum_{i}^{I}\left(\frac{\sum_{n i}^{N i}\left(X_{n i} * b_{n i}\right)}{\sum_{n i}^{N i} b_{n i}} * b_{i}\right)}{B}
$$

where $B$ is the size of census collection district, $b_{n i}$ is the size of a parcel $n$ neighboring parcel $i, I$ is the total number of parcels in the district, and $X_{n i}=1$ if land-use category of neighboring parcel differs from parcel $i$ (0 otherwise). The proposed generalized dissimilarity index can address the limitations of entropy index by considering the micro-scale variation within the neighborhood, and it is not sensitive to the size of the neighborhood. In addition, it can also be applied to all types of land-use data. The dissimilarity index (Equation 2) proposed by Cervero and Kockelman (1997) is a special case of the DIS when the data is available at the hectare gridcell level. Six land-use types are considered for the four methods in the numerical analysis section, including residential, commercial, vacant, institutional/public service, social/recreational, and mining/primary production/agricultural.

Empirical property data from Eastern Adelaide, Australia, is used in Section 5 to compare the performance of the proposed dissimilarity index with those of the entropy index and interaction methods.

\subsection{Property walk accessibility}

A modified FCM method is proposed to calculate a property's accessibility to different destinations by adding a distance decay function in the FCM method. The consideration of the distance decay function can help to overcome the limitation of FCM that within a threshold walking time $\left(d_{0}\right)$ the weight of the potential destinations is based only on its size and not the walking time between them $\left(d_{i j}\right)$. This can address Tobler's first law of geography that "everything is related to everything else, but near things are more related than distant things" (Tobler 1970). The proposed method further addresses all three limitations of using walk score to quantify accessibility, by considering the neighborhood layout, the size (weight) and purpose of the potential destinations, and the total number of potential destinations.

The walk accessibility $A_{i}$ of property $i$ is calculated as follows. Given a property $i$, search all the intended destinations $j$ (e.g., restaurants) within a threshold walking time $\left(d_{0}\right)$. Then,

$$
A_{i}=\sum_{j \in\left\{d_{i j} \leq d_{0}\right)} S_{j} f\left(d_{i j}, d_{0}\right)
$$

where $d_{i j}$ is the walking time between $i$ and $j, f\left(d_{i j}, d_{0}\right)$ represents the distance decay function, and $S_{j}$ is the weight of destination $j$. The distance decay function is usually in the form of a kernel (KD) function (Tobler 1970). The KD function used here is the Epanechnikov function. The Epanechnikov function is written as follows:

$$
\left\{\begin{array}{c}
f\left(d_{i j}, d_{0}\right)=\frac{3}{4}\left[1-\left(\frac{d_{i j}}{d_{0}}\right)^{2}\right], \text { if } d_{i j} \leq d_{0} \\
f\left(d_{i j}, d_{0}\right)=0, \text { if } d_{i j}>d_{0}
\end{array}\right.
$$

Threshold walking times ranging from 5 to 40 minutes, with 5-minute increments, are tested for different types of walk accessibility in the numerical experiments. The threshold walking time indicates that only the destinations within this walking time threshold are considered accessible by walking, and those outside are not.

Empirical property data from Eastern Adelaide, Australia, is used in Section 5 to compare the performance of the proposed modified FCM method with that of the walk score. 


\section{$4 \quad$ Case study data acquisition}

This section discusses the data acquisition for a case study to understand the impact of built environment and property walk accessibility on single-family residential property values. In this study, the Eastern Adelaide Government Region (or the Eastern Adelaide region) was selected for the case study (Figure 2). As shown in Figure 2(a), it is one of four government regions in the much larger Adelaide government region. Unlike the other three regions, the majority of the Eastern Adelaide region belongs to the urban area. It contains 411 census collection districts (CCDs) located in seven cities (Figure 2b). Each CCD represents a neighborhood and contains 220 dwellings, on average. Adelaide city contains the central business district $(\mathrm{CBD})$ of the Adelaide metropolitan region. The city of Prospect is a suburb of the Adelaide metropolitan region and the capital city of South Australia. The city of Unley is the only commercial suburb of the study region. The other four cities are residential suburbs in the Adelaide metropolitan region.
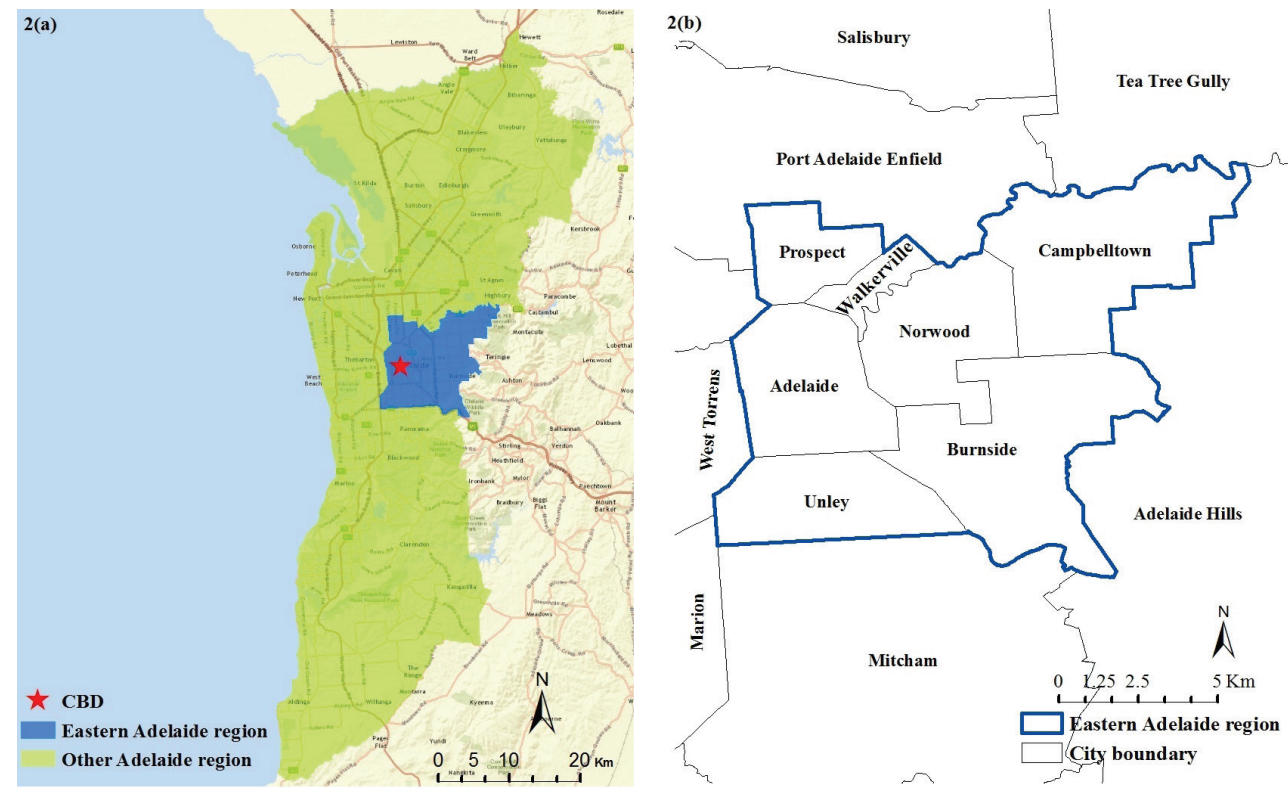

Figure 2: (a) CBD location, Eastern Adelaide region (blue shaded area), and Adelaide region (includes blue and green shaded areas), and (b) local councils in or neighboring the Eastern Adelaide region

Four types of independent variables were considered, including physical characteristics of singlefamily residential properties, social and economic characteristics of the neighborhoods, neighborhood built environment, and property walk accessibility. Based on this, four types of data were collected including census data, road network data, land-use data, and the walking time from selected single-family properties to potential destinations. The census data was collected to measure the variables related to the social and economic characteristics of the neighborhoods, and the road network data was used to compute the neighborhood intersection density, a variable related to the neighborhood built environment. The land-use data was used to provide physical characteristics of single-family residential properties and calculate the neighborhood land-use mix and residential density, two variables related to the neighborhood built environment. The walking times from selected single-family properties to potential destinations were collected to compute different types of property walk accessibility. 


\subsection{Social and economic data}

The social and economic data for each CCD is obtained from the 2006 census data collected by the Australian Bureau of Statistics. It is important to note that census data is collected every five years in Australia; however, for the most recent census (2011), only part of the data is available.

\subsection{Property data and built-environment data}

The land-use data is acquired from the Land Services Group of the Department of Planning, Transport and Infrastructure of Australia. It was collected in 2009 and represents the most current and complete land-use information of the Eastern Adelaide region. It contains more than 30 different attributes (the value of property, the value of land, year built, physical attributes, number of modifications made, etc.) for each property. The road network data was acquired from the South Australia Department of Planning, Transport and Infrastructure; it was also collected in 2009. Residential density, land-use mix (entropy index, interaction index, and generalized dissimilarity index), and intersection density of each CCD are calculated using the land-use data and road network data.

\subsection{Property walk accessibility data and walk score data}

Seven different property walk accessibility types are considered, including walk accessibility to 289 educational locations (schools), 2764 retail stores (groceries, clothes, and hardware), 330 restaurants (coffee shops, restaurants, and bars), 823 social and recreational locations (movie theaters, parks, and fitness centers), 1345 regular bus transit stops, and 3 O-Bahn Busway interchanges in the Eastern Adelaide region. Different types of accessibility were separated because studies (Dai 2011) indicate that accessibility to some destinations has a stronger influence on people's walking behavior compared with other destinations. The traditional walk score does not separate different types of accessibility, but provides a score that weighs them equally. The weights assigned for educational locations, retail stores, restaurants, and social and recreational locations are quantified by the sizes of the parcel. We assume that a location with a larger land size provides greater access to the related activities compared to the same type of location with a smaller land size. The information on the sizes and locations of different types of destinations is based on the database provided by the Land Services Group of the Department of Planning, Transport and Infrastructure of Australia.

The weights of regular bus transit stops and O-Bahn Busway interchanges were assigned based on the bus service frequency at each stop. While the Eastern Adelaide region is not serviced by rail transit services, it is connected by high-speed guided buses known as O-Bahn. O-Bahn Busway operates on specially built tracks and has three interchanges located in the Eastern Adelaide region (Adelaide OBahn 2014). Compared to regular bus transit, O-Bahn Busway serves as a bus rapid transit system with a maximum speed of $62 \mathrm{mph}$. Owen et al. (2007) indicate that the rapid transit system has a larger impact on residential property pricing due to its high service frequency, shorter transit time, and better service quality. The service frequency and locations of regular transit and O-Bahn Busway stops were extracted from Adelaide Metro (Adelaide O-Bahn 2014).

The walking time between a property and its potential destination was measured using the "walk" option on Google Maps between the centroid point of a property land parcel and the centroid point of the destination location land parcel. The shortest walking time is used. Google Maps considers neighborhood topography, physical barriers, and street patterns. This addresses the weakness of measuring the straight-line distance used in the walk score and other methods (e.g., Pivo and Fisher 2009). In addi- 
tion, the traditional methods of measuring walking time depend largely on data availability, as information (such as elevation, street connectivity, and mountain trails) may not be included in a traditional database. Google Maps also enables acquiring more accurate walking time between two locations. One assumption made in the study experiments by using Google Maps to measure walking time is that there is no significant road network and built environment changes between the time that walking time data is collected (in 2014) and the time property value was evaluated (in 2009). Another advantage of using Google Maps is that when the centroid points of the origin and destination land-use parcels are provided to Google Maps, it measures the shortest walking time from the entrance of the origin parcel to the nearest entrance of the destination parcel.

The walk score data of each property was collected in 2014 using the walk score website (https:// www.walkscore.com/).

\section{$5 \quad$ Results and insights}

\subsection{Comparisons of different land-use mix qualification methods}

Figure 3 presents the land-use mix results using the three different methods for 411 census collection districts in the Eastern Adelaide region of Australia. These methods, as discussed in Sections 2.1 and 3.1, are the entropy index (ENT), the interaction index (INT) and the generalized dissimilarity index (DIS).

Six different land-use classes are considered for each method. The highest class, Class 1, represents that this census collection district has a land-use mix, as calculated by a particular method, that is higher than the Eastern Adelaide regional average by two or more standard deviations (SD). Class 2 and Class 3 represent that the census collection district is higher than the Eastern Adelaide region average by one SD but lower than two SDs above average, and higher than the Eastern Adelaide region average but lower than one SD above average, respectively. Class 4 and Class 5 represent the census collection district is lower than the Eastern Adelaide region average but higher than one SD below average, and lower than the Eastern Adelaide region average by one SD but higher than two SDs below average, respectively. Class 6 represents that this census collection district has the lowest level of land-use mix, which is lower than the Eastern Adelaide regional average by two or more SDs. The results of ENT method (Figure 3a) and DIS method (Figure 3c) are similar, since no significant clustering exists in the study area. The INT method results (Figure 3b) are very different from those of the other two methods and significant clustering exists for low levels of land-use mix (Class 6) in the cities of Unley and Campbelltown.

To understand the similarity/dissimilarity of the results of the three land-use mix calculation methods, Spearman's ranked correlation coefficients are computed because in most cases the raw numbers provided by the different land-use mix methods do not have an intuitive or meaningful interpretation by themselves (Song, Merlin, and Rodriguez 2013). Spearman's ranked correlation coefficients are used to statistically compare the results of these three methods. The results are found to be significantly different from each other at the 0.05 significance level. It indicates that the three methods provide different levels of land-use mix for the same neighborhoods located in the study region.

Section 5.2 provides more detailed comparison of these three methods in terms of model performance in estimating the single-family residential property value per equivalent square meter. 

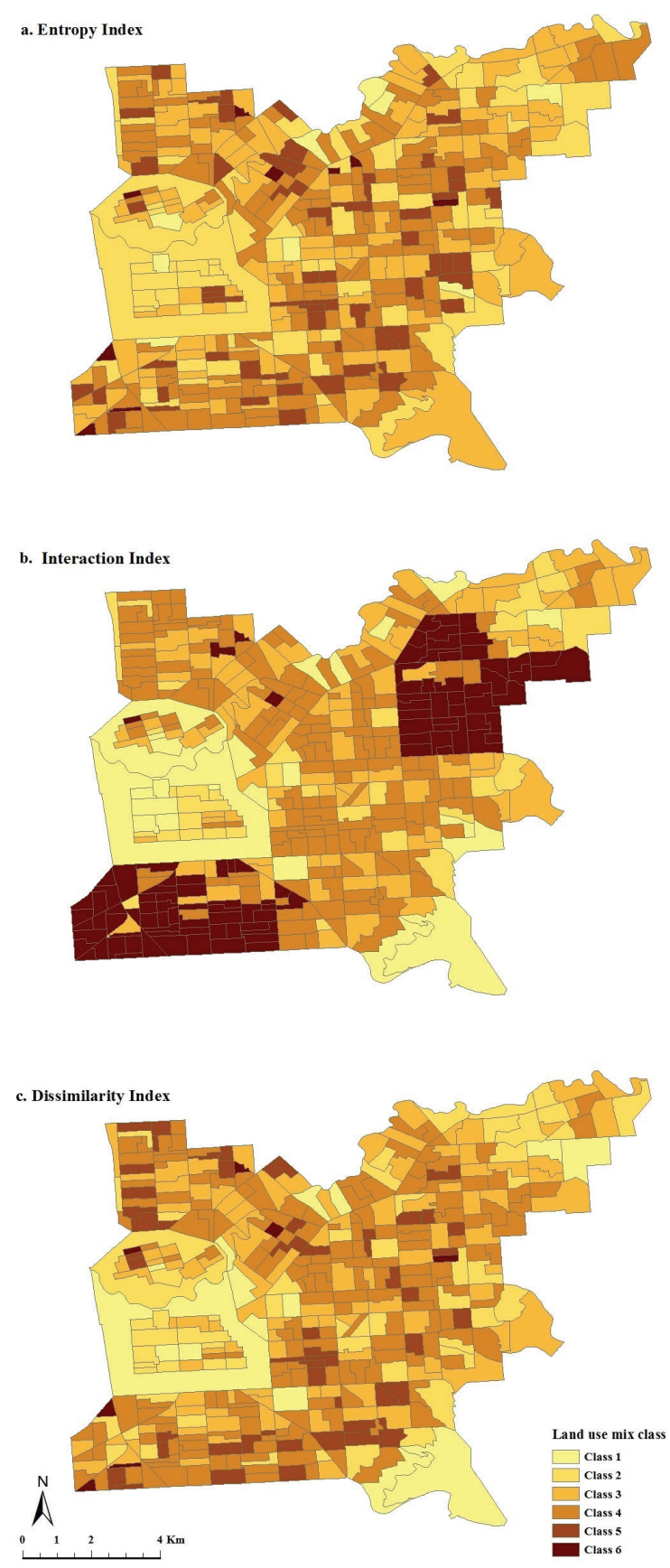

Figure 3: Land-use mix results for using three different methods in the Eastern Adelaide region

\subsection{Comparison of OLS models}

A total of 2700 single-family residential properties were randomly selected for this study in the Eastern Adelaide region and 26 of them were removed due to missing data (such as year built or estimated property value). The dependent variable, the single-family residential property value per equivalent square meter, is the evaluated property value per equivalent square meter in 2009. The single-family residential property value includes both the value of the property and the land value that the property is located in. 
We combine these two values because previous studies (e.g., Glaeser and Gyourko 2003; Kok, Monkkonen, and Quigley 2014) recommend the inclusion of land value in the estimation due to the strong correlation between the value of the property and the value of the land. The equivalent area of a property represents the calculated weighted total area of a property based on the purpose and the construction type of each component in the property. For example, the area of the building under the main roof is included at 100 percent, but the area of the carports is only weighted 33 percent.

To validate the proposed methods to measure land-use mix (the generalized dissimilarity method) and property walk accessibility, a series of seven OLS models were created. The first model is the base model and includes only two types of independent variables, physical characteristics of single-family residential properties, and social and economic characteristics of the neighborhoods. Three other models were created to compare the performances of the proposed generalized dissimilarity index method, the entropy index method, and the interaction index method. Each model contains the same types of independent variables as the base model, as well as residential density and intersection density, and one of the aforementioned land-use mix quantification methods. Two other models were created to compare the proposed property walk accessibility with walk score. They contain the same independent variables as the base model, but one model includes walk score while the other includes the proposed property walk accessibility method. The final model contains all four types of variables, including physical characteristics of single-family residential properties, social and economic characteristics of the neighborhoods, neighborhood built environment, and property walk accessibility.

To compare different model results, the "corrected" Akaike's information criterion (AICc) and adjusted $\mathrm{R}^{2}$ were used as AICc can measure the relative quality of a statistical model for a given set of data by computing the trade-off between the estimate of the goodness-of-fit of the model and its complexity (Brunsdon, Fotheringham, and Charlton 2003). A model with lower AICc values indicates it has a better fit with the observed data and better model performance compared to models with higher AICc values for the same set of data. The adjusted $\mathrm{R}^{2}$ can be used to interpret the proportion of total variance explained by independent variables (Washington et al. 2010). A higher adjusted $\mathrm{R}^{2}$ value implies that the collection of independent variables accounts for a higher percentage of the uncertainty or variation in the single-family residential property value per equivalent square meter. The results of regression parameters of the OLS with the lowest AICc and highest adjusted $\mathrm{R}^{2}$ are shown in Table 1 , which includes all four types of variables. Only estimates of variables that were found to have statistically significant $(\mathrm{p}<0.01)$ correlation with the single-family residential property value per equivalent square meter are included. Further, the variance inflation factor (VIF) of a variable is an indicator of its multicollinearity, and a high VIF value indicates significant multicollinearity. None of the variables having a statistically significant correlation with the single-family property value per square meter has a high VIF, illustrating the low multicollinearity in the OLS regression results shown in Table 1. 
Table 1: OLS regression results

\begin{tabular}{|c|c|c|c|}
\hline Variable & Estimate & t-Statistic & VIF \\
\hline Intercept & 2142.04 & 16.3 & - \\
\hline \multicolumn{4}{|l|}{ Property physical characteristics } \\
\hline $\begin{array}{l}\text { Good condition: } 1 \text { if the property condition is "very good" or "top quality and } \\
\text { excellent", } 0 \text { otherwise }\end{array}$ & 192.9 & 5.4 & 1.4 \\
\hline Property age: The age of the property in year 2009 & 10.3 & 19.6 & 1.7 \\
\hline Symmetrical cottage: 1 if the building style is symmetrical cottage, 0 otherwise & -175.4 & -2.9 & 1.2 \\
\hline Conventional: 1 if the building style is conventional, 0 otherwise & 84.0 & 2.8 & 1.3 \\
\hline \multicolumn{4}{|l|}{ Social and economic characteristics of the neighborhood } \\
\hline$\%$ migrant: Percentage of population born outside Australia & -14.2 & -5.4 & 1.6 \\
\hline$\%$ high prof: Percentage of higher professional occupations in workforce & 28.1 & 15.7 & 2.0 \\
\hline \% no vehicle: Percentage of dwellings that do not have motor vehicle & 13.8 & 5.6 & 1.3 \\
\hline \multicolumn{4}{|l|}{ Built environment of the neighborhood } \\
\hline DIS: Land-use mix index using dissimilarity index method & -97.5 & -3.6 & 1.1 \\
\hline Inter density: Total number of intersections in the census collection district area & -21.7 & 3.2 & 1.2 \\
\hline \multicolumn{4}{|l|}{ Property walk accessibility } \\
\hline $\begin{array}{l}\text { Access to edu: Property walk accessibility to educational (schools) locations with } \\
\text { 40-minute threshold walking time }\end{array}$ & 104.4 & 7.0 & 1.1 \\
\hline $\begin{array}{l}\text { Access to retail: Property walk accessibility to retail (groceries, clothes, and hard- } \\
\text { ware) locations with } 35 \text {-minute threshold walking time }\end{array}$ & 37.0 & 5.3 & 1.4 \\
\hline $\begin{array}{l}\text { Access to soc: Property walk accessibility to social/recreation (parks, recreational } \\
\text { reserves, etc.) locations with } 30 \text {-minute threshold walking time }\end{array}$ & 19.5 & 3.1 & 1.6 \\
\hline \multicolumn{4}{|l|}{ Summary statistics } \\
\hline \multicolumn{4}{|l|}{ Number of observations $=2674$} \\
\hline \multicolumn{4}{|l|}{ Dependent mean = 3394.27 (Australian dollars per equivalent square meter) } \\
\hline \multicolumn{4}{|l|}{ Adjusted $\mathrm{R}^{2}=0.512$} \\
\hline $\mathrm{AICc}=40540.3$ & & & \\
\hline
\end{tabular}

Table 2 compares the base model (without land-use and walk accessibility variables) and the three land-use quantification models and includes variables that are significantly $(\mathrm{p}<0.01)$ correlated with the single-family residential property values per equivalent square meter, AICc values and adjusted $\mathrm{R}^{2}$. 
Table 2: OLS models comparison of the base model and the models with the three different land-use quantification methods

\begin{tabular}{|l|c|c|c|c|}
\hline \multirow{2}{*}{ Variable } & Base Model & ENT & INT & DIS \\
\cline { 2 - 5 } & Estimate & Estimate & Estimate & Estimate \\
\hline Intercept & 2025.8 & 2015.6 & 2025.8 & 2045.6 \\
\hline Good condition & 173.3 & 173.2 & 173.3 & 173.2 \\
\hline Property age & 10.1 & 10.1 & 10.1 & 10.1 \\
\hline Symmetrical cottage & -190.4 & -187.7 & -190.4 & -188.1 \\
\hline Conventional & 134.0 & 126.5 & 134.0 & 128.3 \\
\hline \% migrant & -10.4 & -8.9 & -10.4 & -9.0 \\
\hline \% high prof & 28.8 & 28.0 & 28.8 & 28.4 \\
\hline \% no vehicle & 14.9 & 12.7 & 14.9 & 13.6 \\
\hline Inter density & $--^{*}$ & -24.9 & $--^{*}$ & -37.9 \\
\hline ENT & $--^{*}$ & -48.4 & $--^{*}$ & $--^{*}$ \\
\hline INT & $--^{*}$ & $--^{*}$ & $--^{*}$ & $--^{*}$ \\
\hline DIS & $--^{*}$ & $--^{*}$ & 0.396 & 0.466 \\
\hline Adjusted R & 0.396 & 0.398 & 42929.9 & 41312.3 \\
\hline AICc & 42929.9 & 42921.6 & & \\
\hline
\end{tabular}

Note: --* indicates the variable was not included in the model estimation

--** indicates the variable was not statistically significant for that estimation

As shown in Table 2, the collection of independent variables in the base model (adjusted $\mathrm{R}^{2}=$ 0.396) can only account for about 39.6 percent of the uncertainty or variation in single-family residential property value per equivalent square meter. The model with intersection density and ENT (adjusted $\mathrm{R}^{2}=0.398$ ) can account for only 0.2 percent more uncertainty or variation in the single-family residential property value per equivalent square meter compared to the base model. By contrast, the model with intersection density and DIS (adjusted $\mathrm{R}^{2}=0.466$ ) can account for 7 percent more uncertainty or variation in the single-family residential property value per equivalent square meter compared to the base model. This shows that the proposed DIS improves the goodness-of-fit of the model compared to ENT. In addition, the model with DIS also has a relatively lower AICc compared to the base model and the model with ENT. It indicates that the model with the DIS provides better model performance in estimating the single-family residential property value per equivalent square meter compared to that with ENT.

INT and residential density were not found to have a statistically significant $(p<0.01)$ correlation with the single-family residential property value per equivalent square meter.

The comparisons of the base model and the two models with either walk score or proposed property walk accessibility are shown in Table 3 ; they include the variables that have significant $(\mathrm{p}<0.01)$ correlation with the single-family residential property value per equivalent square meter, AICc values and adjusted $\mathrm{R}^{2}$. 
Table 3: OLS models comparison of base model, walk score and property walk accessibility

\begin{tabular}{|l|c|c|c|}
\hline \multirow{2}{*}{ Variable } & Base Model & Walk Score & Property Walk \\
\cline { 2 - 4 } & Estimate & Estimate & Accessibility Estimate \\
\hline Intercept & 2025.8 & 1819.5 & 2158.2 \\
\hline Good condition & 173.3 & 175.3 & 181.6 \\
\hline Property age & 10.1 & 10.0 & 10.1 \\
\hline Symmetrical cottage & -190.4 & -187.7 & -189.5 \\
\hline Conventional & 134.0 & 100.4 & 123.7 \\
\hline \% migrant & -10.4 & -10.6 & -15.0 \\
\hline \% high prof & 28.8 & 27.9 & 28.9 \\
\hline$\%$ no vehicle & 14.9 & 11.8 & 13.9 \\
\hline Walk Score & $--^{*}$ & 4.1 & $--^{*}$ \\
\hline Access to edu & $--^{*}$ & $--^{*}$ & 96.0 \\
\hline Access to retail & $--^{*}$ & $--^{*}$ & 83.5 \\
\hline Access to soc & $--^{*}$ & $--^{*}$ & 31.2 \\
\hline Adjusted $\mathrm{R}^{2}$ & 0.396 & 0.399 & 0.453 \\
\hline AICc & 42929.9 & 42919.6 & 41369.2 \\
\hline
\end{tabular}

Note: --* indicates the variable was not included in the model estimation

The model with walk score and the same independent variables as the base model can account for only 0.3 percent more uncertainty or variation in the single-family residential property value per equivalent square meter compared to the base model. By contrast, the model with the proposed property walk accessibility (adjusted $\mathrm{R}^{2}=0.453$ ) can account for about 6 percent more uncertainty or variation in the single-family residential property value per equivalent square meter compared to the base model. This shows that the proposed property walk accessibility improves the goodness-of-fit of the model compared to walk score. In addition, the model with property walk accessibility also has a relatively lower AICc compared to the base model and the model with walk score. It indicates that the model with the proposed property walk accessibility provides better model performance in estimating the single-family residential property value per equivalent square meter compared to the other two models.

\subsection{Estimation results of OLS models}

As shown in Table 1,12 variables were found to have a statistically significant $(\mathrm{p}<0.01)$ correlation with the single-family residential property value per equivalent square meter, including four variables related to physical characteristics of the property, three variables related to social and economic characteristics of the neighborhoods, two variables related to neighborhood built environment, and three variables related to property walk accessibility. Section 5.3.1 illustrates the correlation of variables related to physical characteristics of the property and social and economic characteristics of the neighborhoods with the singlefamily residential property value per equivalent square meter. Sections 5.3.2 and 5.3.3 analyze in detail the correlation of the neighborhood built environment and property walk accessibility, respectively, with the single-family residential property value per equivalent square meter.

\subsubsection{Property physical characteristics, social and economic characteristics of neighborhoods, and the single-family residential property value}

Over 30 independent variables related to the physical characteristics of a residential property were considered, including property age at the time of evaluation, last sold date, numbers of modifications made, wall materials, roof materials, number of bedrooms, number of stories, property condition, and property style. Four physical characteristics, including whether property condition is very good or top quality 
and excellent, the age of the property, property style if it is symmetrical cottage, and property style if it is conventional building, were found to have a statistically significant $(\mathrm{p}<0.01)$ correlation with the single-family residential property value per equivalent square meter. The results show that if the property condition is "very good" or "top quality and excellent," it has a positive correlation with property value per equivalent square meter. In the property valuation process, the condition of the property was given on an eight-point Likert scale, from "top quality and excellent" to just "habitable." Since the properties in "very good" or "top quality and excellent" condition suggest good maintenance, these properties are valued higher.

Another observation is that the age of a property at the time of valuation contributes positively to that property's value per equivalent square meter. A possible explanation for this is that mature neighborhoods in urban areas typically lack space for building new single-family residential properties. Since such neighborhoods typically represent the most desirable areas to live given their proximity to many potential destinations of people's activities, these older properties are valued higher.

Two variables related to building style, including property style if it is symmetrical cottage, and property style if it is conventional building, were found to have a statistically significant $(\mathrm{p}<0.01)$ correlation with the single-family residential property value per equivalent square meter. The results indicate that a property with symmetrical cottage building style leads to a lower property value per equivalent square meter, while a property with conventional building style leads to a higher property value per equivalent square meter. Symmetrical cottages were one of the most common style of dwelling in Eastern Adelaide of the 19th century, with general symmetry around a central corridor, and a majority of them were constructed between the 1870s and the 1890s (City of Prospect Planning Department 2014). It is one of the 39 property styles included in the sample and accounts for 7.2 percent of the properties in the sample. A possible explanation for this is that the symmetrical cottage style is not a contemporary style and hence does not add value. The conventional style represents the most common building style (34.1 percent) in the sample. A property with conventional building style can increase property value per equivalent square meter. It suggests that the conventional building style may be a preferred style in the Adelaide region.

Three social and economic variables at the census collection district level were found to have statistically significant $(\mathrm{p}<0.01)$ correlation with the single-family residential property value per equivalent square meter. The positive coefficient of the proportion of higher professional occupations in the workforce reflects that the neighborhood has relatively high-income residents and this factor contributes positively to the residential property value. A neighborhood with a relatively high proportion of migrant population may indicate a relatively low-income neighborhood. A possible explanation is that neighborhoods with higher-income families can afford the typically higher property costs associated with such precincts, while neighborhoods with low-income families cannot.

The proportion of dwellings with no motor vehicles has a statistically significant $(\mathrm{p}<0.01)$ positive correlation with the single-family residential property value per equivalent square meter. A possible explanation is that neighborhoods with a higher percentage of dwellings that do not have personal vehicles are those with a low dependency on a personal vehicle and may have better access to public transit or better bicycling and walking options. These features can contribute positively to the single-family residential property value per equivalent square meter

\subsubsection{Built environment and the single-family residential property value}

The OLS results indicate that land-use mix has a statistically significant negative correlation with the single-family residential property value per equivalent square meter (Table 1), suggesting that a relatively higher land-use mix would reduce the single-family residential property value per equivalent square me- 
ter. Several previous studies (e.g., Aurand 2010) used similar results generated by other global regression models to explain the correlation of land-use mix and property value, and conclude that offering a more diverse land use can potentially provide affordable housing. It indicates that larger or intense development of commercial, institutional/public service, and mining/primary production/agricultural property development (high land-use mix) can potentially reduce the single-family residential property value per equivalent square meter. This is because residents may have a negative view of these developments in the neighborhood due to the associated social and environmental costs.

The other variable found to have a statistically significant correlation with the single-family residential property value per equivalent square meter is intersection density. The OLS results suggest that it has a significant negative correlation (Table 1) with the single-family residential property value per equivalent square meter. It indicates that in general a relatively high intersection density would reduce the single-family residential property value. A possible explanation is that more intersections in a neighborhood (high intersection density) may be indicative of more traffic and congestion.

\subsubsection{Property walk accessibility and the single-family residential property value}

Six types of residential property walk accessibilities were considered corresponding to six different potential destinations. For each type of property walk accessibility, threshold walking times were tested, ranging from 5 to 40 minutes with 5-minute increments. However, only three property walk accessibility variables with specific threshold walking times were found to have a statistically significant correlation with the single-family residential property value per equivalent square meter (Table 1), including walk accessibility to education locations, walk accessibility to retail locations, and walk accessibility to social and recreational locations. All of them are positively correlated with the single-family residential property value per equivalent square meter, indicating that walk accessibility has a positive impact on property value. Other tested thresholds, when included, either reduced the overall model goodness-of-fit or were found to not be statistically significant $(\mathrm{p}<0.01)$. These results also suggest that different types of walk accessibility should be separated to understand their specific impacts on residential property values.

\section{Concluding comments}

This study aims to quantify the impact of built environment and property walk accessibility on singlefamily residential property values. Previous quantitative studies on the impact of built environment and walk accessibility on residential property values have key limitations in terms of quantifying built environment and walk accessibility. To address these limitations, a generalized dissimilarity index, which is not limited by the data recorded type used in practice, is introduced to quantify land-use mix, a key component of built environment. The study also presents a new approach to measure a property's walk accessibility, which factors neighborhood topology, physical barriers, street patterns, and the size and total number of potential destinations. A case study is conducted using empirical data in the Eastern Adelaide region of Australia.

The performances of the proposed generalized dissimilarity index and the property walk accessibility method in estimating the single-family residential property value per equivalent square meter were compared to those of other commonly-used land-use mix quantification and walk-accessibility methods. The proposed methods outperformed other methods in terms of goodness-of-fit and explanatory power.

Twelve variables were found to have a statistically significant correlation with the single-family residential property value per equivalent square meter, including four variables related to the physical characteristics of the property, three variables related to the social and economic characteristics of the 
neighborhoods, two variables related to the neighborhood built environment, and three variables related to the property walk accessibility.

As illustrated by Table 1, walkable environment has mixed impacts on single-family residential property value per equivalent square meter. On the one hand, some features of walkable environment such as high land-use mix or intersection density can potentially reduce the single-family residential property values per equivalent square meter. On the other hand, other features of walkable environment in terms of high property walk accessibility to education, retail, and social and recreational locations can potentially increase the single-family residential property values per equivalent square meter. These results suggest that the single-family residential property value per square meter is higher in homogeneous residential neighborhoods (low land-use mix) with well-distributed education, retail, and social and recreational locations (high property walk accessibility). It also indicates that larger or intense commercial, institutional/public service, and mining/primary production/agricultural properties (high land-use mix) can have a negative effect on the single-family residential property value per equivalent square meter in the neighborhood.

The study analysis suggests that the following factors should be considered by planners to design neighborhoods featuring better walkable environment: 1) intense commercial, institutional/public, and manufacturing developments in a neighborhood (high land-use mix) should be avoided and new developments should be scaled in size to fit the neighborhood (low land-use mix); 2) dense road networks should be avoided (high intersection density), and pedestrian sidewalks can offer better access to pedestrians in the neighborhood (high property walk accessibility); and 3) new businesses, social and recreational areas, and education locations need to be carefully allocated, as they can be beneficial to single-family properties in the neighborhood (high property walk accessibility).

The study analysis also suggests that the following aspects of single-family residential property and the associated environment can aid the property investment strategies of investors: 1) maintaining older single-family residential properties with "very good" or above condition can potentially increase property values; 2) understanding the building style preference of a region, since certain building styles can increase and/or decrease the single-family residential property values; 3 ) investing in neighborhoods that have people with high professional occupations and/or low automobile dependency; 4) avoiding neighborhoods with intense commercial, institutional/public, and manufacturing developments (high land-use mix), and/or dense road networks (high intersection density); and 5) investing in single-family residential properties with close proximities to education, retail, and social and recreational locations.

A limitation of this study is that the evaluated property value of the single-family residential property is used as opposed to the sale value due to the non-availability of such data. This study focuses on the development and validation of the proposed generalized dissimilarity index for quantifying land-use mix, a key component of built environment, and a new method for measuring a property's walk accessibility, and links them to single-family residential property values. The two proposed methods address the limitations of the methods used in previous studies and outperform other commonly used land-use mix and walk accessibility methods in estimating the empirical property data in Eastern Adelaide, Australia, in terms of the goodness-of-fit and explanatory power. Thereby, this study lays the foundation for a more comprehensive study that focuses on understanding the potential similarities and dissimilarities in terms of the impacts of walkable environment on single-family and multi-family residential property values.

The various findings and insights from this study can be used to assist planners to efficiently plan and implement neighborhood development planning so that the potential impact on the single-family residential values in the affected areas can be addressed. It can also be used to assist private investors to make more informed decisions on real estate investment in single-family residential properties. 


\section{Acknowledgments}

This study is based on research supported by the NEXTRANS Center, the USDOT Region 5 University Transportation Center at Purdue University. The authors also thank Shubham Agrawal of Purdue University for help with the walk-time data collection process. Any errors or omissions remain the sole responsibility of the authors. 


\section{References}

Adelaide O-Bahn. 2014. O-Bahn Busway Weekly Schedule. https://www.adelaidemetro.com.au/Timetables-Maps/Special-Services/Adelaide-O-Bahn.

Aurand, A. 2010. Density, housing types and mixed land use: Smart tools for affordable housing? Urban Studies 47(5): 1015-1036.

Boyle, A., C. Barrilleaux, and D. Scheller. 2013. Does walkability influence housing prices? Social Science Quarterly 95: 852-867.

Brunsdon, C., S. Fotheringham, and M. Charlton. 2003. Geographically Weighted Regression: The Analysis of Spatially Varying Relationships. Hoboken, NJ: John Wiley and Sons.

Cerin, E., D. J. Macfarlane, H. H. Ko, and K. C. A. Chan. 2007. Measuring perceived neighborhood walkability in Hong Kong. Cities 24(3): 209-217.

Cervero, R., and K. Kockelman. 1997. Travel demand and the 3Ds: Density, diversity, and design. Transportation Research Part D: Transport and Environment 2(3): 199-219.

Chen, Y., S. Ravulaparthy, K. Deutsch, P. Dalal, S. Y. Yoon, T. Lei, K. G. Goulias, R. M. Pendyala, C. R. Bhat, and H. H. Hu. 2011. Development of indicators of opportunity-based accessibility. Transportation Research Record 2255: 58-68.

City of Prospect Planning Department. 2014. Historic zone and local heritage places. http://www. prospect.sa.gov.au/webdata/resources/files/City $\% 20$ of $\% 20$ Prospect $\% 20$ Historic $\% 20$ (Conservation)\%20Zone\%20and\%20Local\%20Heritage\%20Places\%20-\%20Design\%20Guidlines.pdf.

Congress of New Urbanism. 2014. What is Congress of New Urbanism? http://www.cnu.org/who_we_ are.

Dai, D. 2011. Racial/Ethnic and socio-economic disparities in urban green space accessibility: Where to intervene? Landscape and Urban Planning 102(4): 234-244.

Ewing, R., and R. Cervero. 2010. Travel and the built environment: A meta-analysis. Journal of American Planning Association 76(3): 265-294.

Ewing, R., and F. Rong. 2008. The impact of urban form on US residential energy use. Housing Policy Debate 19(1): 1-30.

Frank, L. D., B. Stone, and W. Bachman. 2000. Linking land use with household vehicle emissions in the central Puget Sound: Methodological framework and findings. Transportation Research Part D: Transport and Environment 5(3): 173-196.

Frank, L. D., J. F. Sallis, B. E. Saelens, L. Leary, K. Cain, T. L. Conway, and P. M. Hess. 2010. The development of a walkability index: Application to the neighborhood quality of life study. British Journal of Sports Medicine 44(13): 924-933.

Glaeser, E. L., and J. Gyourko. 2003. The impact of building restrictions on housing affordability. Federal Reserve Bank of New York Economic Policy Review 9: 21-39.

Kok, N., P. Monkkonen, and J. Quigley. 2014. Land use regulations and the value of land and housing: An intra-metropolitan analysis. Journal of Urban Economics 81: 136-148.

Lee, C., and A. V. Moudon. 2006. The 3Ds + R: Quantifying land use and urban form correlates of walking. Transportation Research Part D: Transport and Environment 11(3): 204-215.

Levine, J., and A. Inam. 2004. The market for transportation-land use integration: Do developers want smarter growth than regulations allow? Transportation 31: 409-427.

Leyden, K. M. 2003. Social capital and the built environment: The importance of walkable neighborhoods. American Journal of Public Health 93(9): 1546-1551.

Manaugh, K., and T. Kreider. 2013. What is mixed use? Presenting an interaction method for measuring land use mix. The Journal of Transport and Land Use 6(1): 63-72. 
Matthews, J. W., and G. K. Turnbull. 2007. Neighborhood street layout and property value: The interaction of accessibility and land use mix. The Journal of Real Estate Finance and Economics 35(2): 111-141.

McCormack, G. R., A. Shiell, B. Giles-Corti, S. Begg, J. L. Veerman, E. Geelhoed, A. Amarasinghe, J. C. H. Emery. 2012. The association between sidewalk length and walking for different purposes in established neighborhoods. International Journal of Behavioral Nutrition and Physical Activity 9(1): 92.

Owen, N., E. Cerin, E. Leslie, L. DuToit, N. Coffee, L. D. Frank, A. E. Bauman, G. Hugo, B. E. Saelens, and J. F. Sallis. 2007. Neighborhood walkability and walking behavior of Australian adults. American Journal of Preventive Medicine 33(5): 387-395.

Pivo, G., and J. Fisher. 2009. Effects of walkability on property values and investment returns. Responsible Property Investing Center. Working Paper. Boston College and University of Arizona Benecki Center of Real Estate Studies, Indiana University.

Rodríguez, D. A., K. R. Evenson, A. V. Roux, and S. J. Brines. 2009. Land use, residential density, and walking: The multi-ethnic study of atherosclerosis. American Journal of Preventive Medicine 37(5): 397-404.

Saelens, B. E., J. F. Sallis, and L. D. Frank. 2003. Environmental correlates of walking and cycling: Findings from the transportation, urban design, and planning literatures. Annals Behavioral Medicine 25(2): 80-91.

Song, Y., and G. Knaap. 2004. Measuring the effects of mixed land use on housing values. Regional Science and Urban Economics 34(6): 663-680.

Song, Y., L. Merlin, and D. Rodriguez. 2013. Comparing measures of urban land use mix. Computer, Environment and Urban Systems 42: 1-13.

Tobler, W. 1970. A computer movie simulating urban growth in the Detroit region. Economic Geography 46(2): 234-240.

Washington, S. P., M. G. Karlaftis, and F. L. Mannering. 2010. Statistical and Econometric Methods for Transportation Data Analysis. Boca Raton, FL.: CRC Press.

Walk Score. 2014. Walk score methodology. http://www.walkscore.com/methodology.shtml. 